\title{
Paraplegia
}

\section{Gastrostomy for Gaseous Decompression in Quadriplegic Man: Case Report}

B.C. Cosman, MD, MPH, G.H. Sullivan, MD, D.L. Johnson, MD, I. Perkash, MB, BS, MS, FRCS (Edin), FRCS (Eng)

'Spinal Cord Injury Service, Department of Surgery, Department of Veterans Affairs Medical Center, 3801 Miranda Avenue, Palo Alto, California 94304, USA.

\section{Summary}

A case of percutaneous endoscopic gastrostomy in a quadriplegic patient with aerophagia and symptomatic chronic gastric distention is presented. Gastrostomy is an accepted procedure for acute and chronic gastric distention in veterinary medicine. In the aerophagic quadriplegic population, this is a viable therapeutic option after failure of medical therapy.

Aerophagia in the adult quadriplegic is a significant clinical problem for which no definite treatment exists. Gastrostomy for feeding and decompression is an established surgical procedure for various indications, and veterinary surgeons employ it to relieve acute and chronic gaseous distention in cattle and dogs. We present a case in which percutaneous endoscopic gastrostomy (PEG) was performed for relief of symptomatic gastric distention in a high-risk quadriplegic patient whose abdominal pain and bloating due to aerophagia were refractory to medical management.

In our experience in a Department of Veterans Affairs Spinal Cord Injury Center, we have noted chronic gastric dilatation in many quadriplegic patients, apparently due to aerophagia, and we have treated several patients medically for upper abdominal pain and bloating. It is interesting to speculate whether this condition is caused by a gastro-pyloric dyssynergia analogous to the bladder and anorectal dyssynergias found in spinal cord injury patients, and whether inability to belch through unchecked diaphragmatic pressure on the oesophagus is a contributing factor. The preponderance of older individuals with this condition may point to an aetiologic role for chronic anticholinergic administration in gastric hypotony and hypomotility.

Acute gastric dilatation due to aerophagia has been recognised in the young quadriplegic (Sutton et al., 1981) and is a life-threatening late complication of spinal cord injury that may cause aspiration, respiratory compromise, and vagally mediated bradycardia. Whether acute and chronic gastric dilatation due to aerophagia share a common mechanism is unknown. 
We have used oral simethicone, an antifoaming agent, for outpatient treatment of chronic aerophagic distention, with metoclopramide as the second line of therapy. Intermittent nasogastric intubation is occasionally required. We report a case in which we peformed PEG for relief of distention when it proved refractory to medical therapy.

\section{Case summary}

A 66-year-old man had suffered a C5/6 spinal cord injury in a construction accident 30 years prior to admission. He had been followed in our unit for the past 10 years and was wellknown to our service. His underlying medical problems included chronic obstructive pulmonary disease, peripheral vascular disease, recurrent right pyelonephritis, neuropathic bladder, and autonomic dysreflexia with labile hypertension. Previous operations included bilateral epididymectomies, left iliac angioplasty, left fifth ray amputation, and several procedures for treatment of nephrolithiasis. Colonoscopy 22 months prior to admission was a normal study. His most recent operation was a right partial nephrectomy 17 months prior to admission; this was complicated by a cardiac arrest in the immediate post-operative period from which he was successfully resuscitated.

Ten months prior to admission, he began to complain of abdominal bloating and crampy pain, worse at night and after meals, with concomitant respiratory distress. Persistent hiccoughing accompanied painful exacerbations, and the patient stated that he was unable to belch. There was no relief from passing flatus. Abdominal X-rays taken during emergencyroom visits for left upper quadrant pain and distention showed a dilated, gas-filled stomach (Fig. 1). Simethicone therapy had no effect, and the patient was treated with metoclopramide $10 \mathrm{mg}$ po $\mathrm{q} 8 \mathrm{~h}$ for 8 months with minimal clinical improvement. Prior to admission he had required intermittent nasogastric intubation at home, with relief of pain and distention.

PEG was performed under local anaesthesia in May 1989. An 18 French Flexiflo ${ }^{\circledR}$ SacksVine $^{\mathrm{TM}}$ gastrostomy tube (Ross Laboratories, Columbus, Ohio, USA) was placed without incident. Abdominal girth decreased from $100 \mathrm{~cm}$ pre-operatively to $95 \mathrm{~cm}$ post-operatively. Metoclopramide was discontinued post-operatively. The tube was unplugged on post-op day

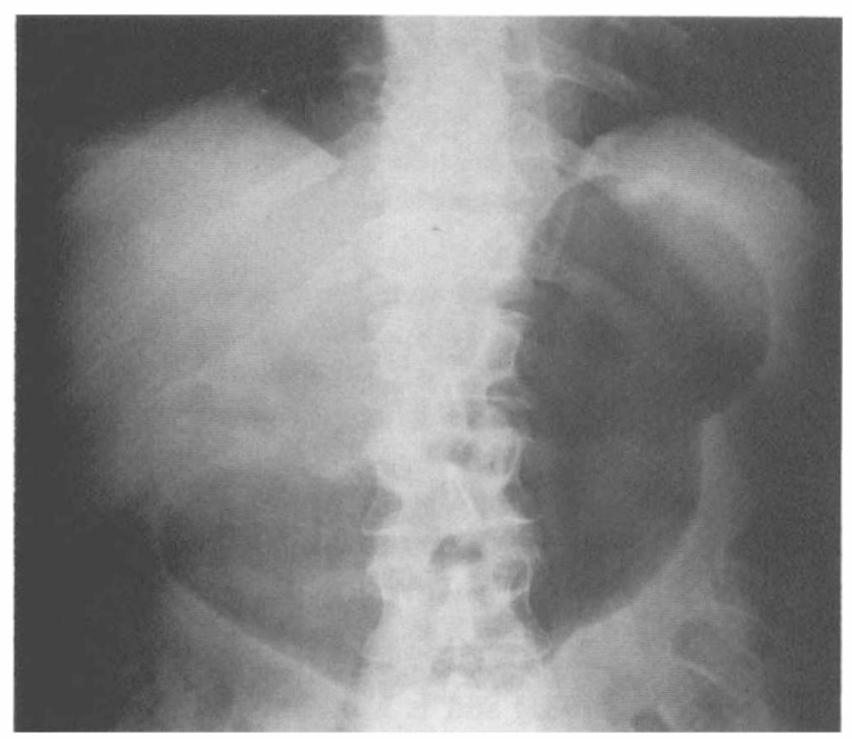

Figure 1 Abdominal X-ray taken during an episode of bloating and pain 6 months prior to the procedure. 


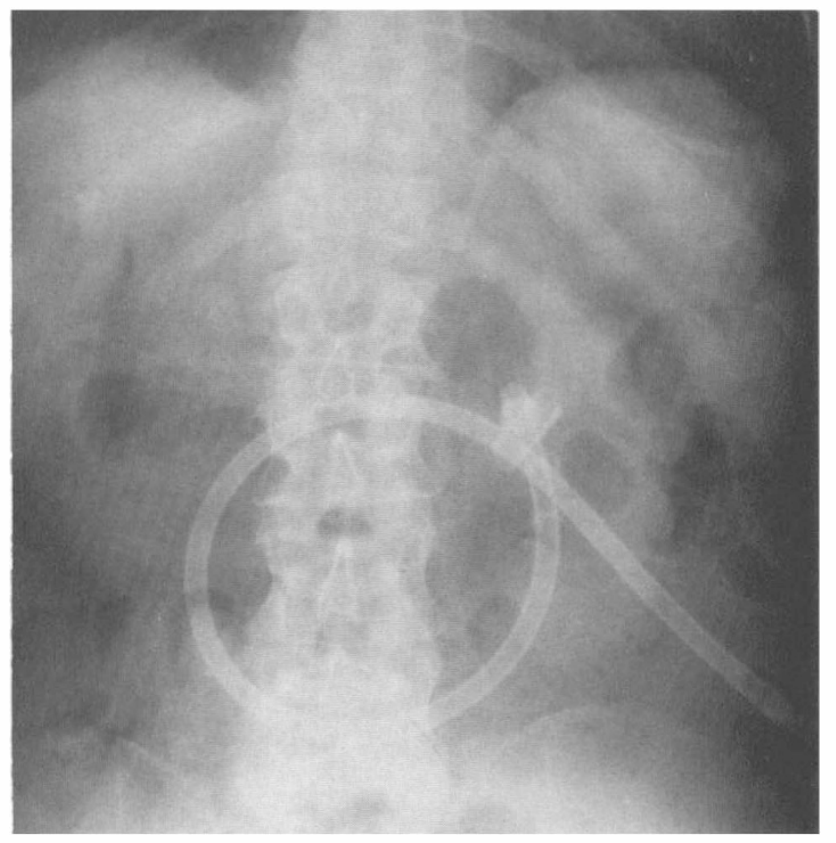

Figure 2 Abdominal X-ray taken on post-operative day 8, after PEG and decompression.

3, and air and a small amount of gastric contents were expressed. Thereafter the patient started a regimen of unplugging the tube twice a day for a half-hour. He visited the emergency-room on post-op day 8 for an episode of pain and distention similar to those he had pre-operatively; he was decompressed via the gastrostomy tube (Fig. 2) and instructed to unplug it twice a day for an hour and additionally as needed.

He has done well for 4 months on this regimen and notes a marked decrease in pain and distention, increased ability to sleep and do daily tasks, no change in hiccoughing, and an increase in involuntary belching. Unplugging the tube yields an audible rush of air. The plan is to maintain the tube in its present position for the patient's lifetime.

\section{Discussion}

The use of gastrostomy for temporary decompression as an alternative to nasogastric suction after major intra-abdominal operations was popularised in the late 1950's (Farris and Smith, 1956), and remains a controversial option to this day (Pricolo et al., 1989). PEG was introduced in 1980 (Gauderer et al., 1980) and has become an established procedure for gastric decompression and feeding (Miller $e t$ al., 1986). The use of PEG for long term gastrointestinal decompression in patients with chronic obstruction has been reported (Stellato and Gauderer, 1987).

Gaseous gastric distention is found elsewhere in the animal kingdom and is often treated with gastrostomy by veterinary physicians. Cattle develop ruminal tympany ('bloat'), a life-threatening gaseous distention due either to dietary factors or obstruction (Blood et al., 1983). Self-retaining trocars are used for emergency treatment of acute bloat (Nguhiu-Mwangi and Byagagaire, 1988), and veterinary surgeons perform a rumen fistula, equivalent to operative gastrostomy for chronic bloat (Anderson and Frederiksen, 1976). Chronic bloat may be treated with percu- 
taneous rumenostomy, with external tubing left in place to ensure continued expression of gas (Filipov and Lock, 1979).

Dogs develop gastric dilatation-volvulus, an acute, life-threatening syndrome that requires gastric decompression (Orton, 1986). Emergency treatment consists of gastrocentesis, then orogastric intubation and/or gastrostomy (Johnston, 1977). A tube gastrostomy may be placed for further decompression (Parks, 1979). In dogs as in humans, nasogastric intubation and gastrostomy are rival procedures (Crowe, 1986).

Pathological aerophagia is seen almost exclusively in children and in mentally ill adults (Holburn, 1986). In their review on pathological childhood aerophagia, Gauderer et al. (1981) state that simethicone and nasogastric intubation were temporarily useful, and operative gastrostomy was carried out in patients with equivocal results. In these cases, aerophagia improves with counselling, psychotherapy, and time. In contrast, aerophagia in quadriplegics is a physio-anatomical problem which does not resolve spontaneously and which requires treatment when symptomatic.

We report a case in which a high-risk quadriplegic with symptomatic aerophagia and bloating was treated successfully with PEG. This constitutes a new indication for this established procedure. We feel that similar patients who have documented gaseous gastric distention, are symptomatic, and have failed medical therapy, should be offered this relatively benign surgical procedure.

\section{References}

ANDERSON JF, FREDERIKSEN ED 1976 Surgical fistula as an aid in the treatment of chronic bloat in cattle. Veterinary Medicine and Small Animal Clinician 71:1363-1367.

BLOOD DC, RADOSTITS OM, HENDERSON JA 1983 Ruminal tympany (bloat). In: Veterinary Medicine: $A$ Textbook of the Diseases of Cattle, Sheep, Pigs, Goats and Horses, 6th edn. Baillière Tindall, London, pp 239-246.

Crowe DT Jr 1986 Use of a nasogastric tube for gastric and esophageal decompression in the dog and cat. Fournal of the American Veterinary Medical Association 188:1178-1182.

FARRIS JM, SMITH GK 1956 An evaluation of temporary gastrostomy: a substitute for nasogastric suction. Annals of Surgery 144:475-486.

FILIPOV MM, LOCK TF 1979 Implantation of plastic tubing for treatment of chronic bloat in cattle. Fournal of the American Veterinary Medical Association 175:211-212.

GAUDERER MWL, PONSKY JL, IZANT RJ JR 1980 Gastrostomy without laparotomy: a percutaneous endoscopic technique. Fournal of Pediatric Surgery 15:872-875.

GAUDERER MWL, HALPIN TC JR, IZANT RJ JR 1981 Pathologic childhood aerophagia: a recognizable clinical entity. Fournal of Pediatric Surgery 16:301-305.

HolBURN CS 1986 Aerophagia: an uncommon form of self-injury. American fournal of Mental Deficiency 91:201-203.

JoHNSTON DE 1977 Treatment of gastric dilatation and torsion in the dog. In: Kirk RW, ed., Current Veterinary Therapy VI: Small Animal Practice. W.B. Saunders, Philadelphia, pp 936-939.

Miller RE, Kummer BA, Tiszenkel HI, Kotler DP 1986 Percutaneous endoscopic gastrostomy: procedure of choice. Annals of Surgery 204:543-545.

NGUHIU-MWANGI JA, ByagagaIRE SD 1988 Unusual cause of acute frothy bloat and complications of rumen puncture. Modern Veterinary Practice 69:33-34.

ORTON EC 1986 Gastric dilatation-volvulus. In: Kirk RW, ed, Current Veterinary Therapy X: Small Animal Practice. W.B. Saunders, Philadelphia, pp 856-862.

PARKS J 1979 Surgical management of gastric torsion. Veterinary Clinics of North America: Small Animal Practice 9:259-267.

Pricolo Ve, Vittimberga GM, Yellin SA, Burchard KW, Slotman GJ 1989 Decompression after gastric surgery: gastrostomy versus nasogastric tube. American Surgeon 55:413-416.

STELlato TA, GAUDERER MWL 1987 Percutaneous endoscopic gastrostomy for gastrointestinal decompression. Annals of Surgery 205:119-122.

SutTON RA, MACPHAIL I, BENTLEY R, NANDY MK 1981 Acute gastric dilatation as a relatively late complication of tetraplegia due to very high cervical cord injury. Paraplegia 19:17-19. 